\title{
Calculative regimes in the making: implementation and consequences in the context of Austrian public universities
}

\author{
Michael Habersam and Martin Piber \\ Faculty of Business and Management, University of Innsbruck, \\ Innsbruck, Austria, and \\ Matti Skoog \\ Stockholm Business School, Stockholm University, Stockholm, Sweden
}

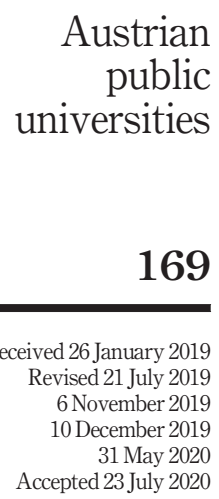

Accepted 23 July 2020

\begin{abstract}
Purpose - This study aims to answer the research question of how a calculative regime for public universities is implemented, how and under which conditions its symbolic use emerges and what kind of unintended consequences occur over time.

Design/methodology/approach - The empirical material presented in the paper derives methodically from a longitudinal qualitative research approach analyzing higher education systems (HES)-reforms in Austria. To better understand the consequences of the organizational changes in line with the new legal framework, 2 series of qualitative interviews in 2011/2012 and 2016/2017 on the field level and the organizational level were conducted.

Findings - Identifying two enabling consequences from the tactical behaviors of resistance and symbolic use, i.e. new processes of communication and horizontal network building, allows for theorybuilding with a focus on the dynamics how accounting begins, then next becomes an established infrastructure, is then destabilized and re-elaborated before it becomes, again, an infrastructure which is different from before.

Research limitations/implications - Although the findings are based on a national empirical context, they are linked to the international discourse on HES in transition and the role of calculative regimes including performance measurement and management attitudes and instruments. They are relevant for an international research community open-minded toward differentiated case studies in a longitudinal perspective on HES-reforms.

Practical implications - When reflecting on their own specific settings governing bodies and practitioners managing the transition of HES may find insights from longitudinal case studies inspiring. The dynamics initiated by new calculative regimes installed need a sensitive framework to handle dissent, resistance, tactical behaviors and changes in power relations between the field level and the organizational level.
\end{abstract}

(C) Michael Habersam, Martin Piber and Matti Skoog. Published by Emerald Publishing Limited. This article is published under the Creative Commons Attribution (CC BY 4.0) licence. Anyone may reproduce, distribute, translate and create derivative works of this article (for both commercial and non-commercial purposes), subject to full attribution to the original publication and authors. The full terms of this licence may be seen at http://creativecommons.org/licences/ by/4.0/legalcode

Authors would like to thank all discussants at the Kozminski QRAMJ-workshop in 2018 at Kozminski University Warsaw, Martin Messner and our two reviewers who supported authors with the right "twist" at the right time.

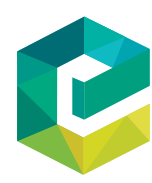

Qualitative Research in Accounting \& Management Vol. 18 No.2 202 18 No. 2, 2021 pp. 169-194
Emerald Publishing Limited 1176-6093 DOI 10.1108/QRAM-01-2019-002 
QRAM

18,2

Originality/value - This is a unique longitudinal case study of the Austrian HES and its public universities in transition.

Keywords Resistance, Public universities, Power, Longitudinal case study, Calculative regimes, Symbolic use

Paper type Research paper

\section{Introduction}

This article is centered around a longitudinal case study on reforms in the higher education system (HES) of Austria initiated around the turn of the millenium. The changes in legal frameworks were profound and labeled later on the most comprehensive Austrian HESreform since mid of 19th century (Fraenkel-Haeberle, 2014). What happened in the past two decades and why?

In general, the Austrian reform ambitions neatly fit into the predominant new public management (NPM)-rationale (Power, 1994; Hood, 1995) and a more and more globalized pressure toward isomorphism in HES-governance (Townley, 1997; Cai, 2010). Selling education as a branded commodity in a mass market (Parker, 2011, 2013) provokes an altered notion of "control" and "good performance." To survive in competitive environments (Erkkilä and Piironen, 2014), autonomy is needed, but combined with extended accountability on value-formoney (Gornitzka and Maassen, 2017), positioning in (international) rankings and achieving customer satisfaction - or employability - key performance indicators (KPIs). When governments cut funding per student and understand themselves as "remote controller" (Parker, 2011), financial management becomes an end in itself (Parker, 2012). Within individual universities, internal governance structures are less oriented towards collegial decision-making (McNay, 1995) but tend to become business-like, monocratic, centralized and less academically free despite organizational autonomy, what Kallio et al. (2020) call a competitive bureaucracy. For an actual literature-review on the HES-metamorphosis see Argento et al. (2020), a broader perspective on knowledge intensive public organizations is provided by Grossi et al. (2020).

The recipe to develop the Austrian HES further comprised many ingredients: autonomy and internal managerial control is combined with accountability and external legitimation. The motivation was to create organizations striving for efficiency and effectiveness while competing for primarily public and (to a lesser extent) private financial resources. In addition, being attentive of worldwide rankings and benchmarking should result in an internationally competitive Austrian HES (Habersam et al., 2013, 2018).

Increased organizational autonomy, however, came right from the beginning with a new governance approach in terms of performance measurement and management (PMM). The Austrian Federal Ministry of Education, Science and Research (hereinafter: the Ministry) as main protagonist and the individual public universities negotiate performance contracts. These negotiations refer basically to an indicator-set of a mandatory performance reporting system called "Wissensbilanz" (knowledge balance sheet (KBS)). Negotiations on performance backed by KBS-data characterize the new calculative regime installed by the Ministry.

The term "calculative regime" is chosen because it refers to a broader discourse on accounting as social and institutional practice taking place in very specific contexts. There has been a rich literature in accounting for decades thematizing the consequences emerging when a new calculative regime is installed, becomes used and later on an established infrastructure (Burchell et al., 1980; Hopwood, 1983, 1987; Miller and Rose, 1990; Hopwood, 1992; Miller, 1992, 1994; Miller and O'Leary, 1994; Power, 1994, 1997; Potter, 2005; Power, 2015). This discourse clearly indicates an impact of accounting beyond being a neutral technique to assure rational decision-making in organizations and society (Mouritsen, 1994). Unsurprisingly, the literature on HES-reforms and 
change in public universities can be divided into firstly the literature on intended rational decision-making and supportive instrumental use of calculative regimes, and secondly literature which analyzes alternate forms of use and unintended consequences after a new calculative regime is put in place. We are interested to contribute to the latter. A public university has to combine different logics of action and actors in the field of research, teaching and third mission by the modus operandi "and" instead of "either-or." In such a multi-stakeholder-organization the Weberian ideal of rationality, its promise of functionality, transparency, effective and efficient achievement of pre-defined goals may not be fulfilled to full extent. In a first attempt to grasp possible alternate forms of use and unintended consequences, Piber and Pietsch (2006) addressed the symbolic use of PMM in the Austrian HES at an early stage. One and a half decade later we refer once more to this "thread of research" but with specific interest in effects emerging after the beginning was set formally by decree in 2006. Insofar, this longitudinal study is guided by the research question how a calculative regime for public universities is implemented and what kind of - to some extent unintended - consequences its symbolic use triggers over time.

The notion "triggers over time" is one aspect that makes the Austrian case specific and interesting. To accompany an HES-change process for over one and a half decades is a promising research-setting. To interpret data from different points in time reveals the dynamics of the interplay between internal and external actors dealing with exogenous and endogenous pressures according to their respective perceptions. Resistance to and symbolic use of PM over time can trigger enabling consequences despite aspects of coerciveness to be expected due to the mandatory character of the PMM installed. These insights which are elaborated in the fourth chapter contribute to a specific strand of literature presented in the next chapter in detail. Other contributions are of conceptual nature. Power (2015) focuses on the beginning of an accounting concept at UK universities. He analyses the Impact Case Study (ICS) and accompanies its emergence and operationalization till it becomes an infrastructure. He argues for a four-phases model to support theory-building, explained in more detail in the literature review in the next chapter. By reflecting on the Austrian case we adapt this model by stretching the accounting event window toward the period after an infrastructure became stabilized for the first time. Ongoing disruption partly provoked by dissent in perception and changes in power relations open up new spaces for maneuver filled by diverse tactical behaviors over time. To integrate these aspects into an adapted basic fourphase model sheds light on the dynamic and sometimes fragile character of calculative regimes in the making.

As mentioned above and to follow our guiding research question, Section 2 presents the relevant literature to better understand symbolic use and its consequences. The literature review provides for a basic conceptual model to orient the analysis of the case and to systematize its inductively generated insights with some reference to methodological considerations. In Section 3 the Austrian case is presented. Section 4 discusses the empirical evidence with reference to the literature and the basic conceptual model. Section 5 presents contributions and some aspects of future research are outlined at the end of the article.

\section{Literature}

In the past decades, the ideas of NPM also entered the higher education sector. Insofar, performance measurement and performance management have become more and more important. New institutionalist approaches discern a technical context and symbolic context of social practices. Also, performance measurement systems can be and are analyzed out of these two perspectives, namely, on the one hand, they are implemented out of the rational idea to evaluate the implementation of set targets and to improve the effectiveness of organizations. On the other hand, they are used to display the conformity with seminal 
QRAM 18,2

societal norms and values. Piber and Pietsch (2006) outline this legitimating function of the KBS toward external stakeholders. "Moreover, the adoption of performance measurement practices in universities such as the KBS can be interpreted as an expression of a comprehensive isomorphic change in the organizational field of universities (and public institutions in general). Under the pressure of "modernization," the efforts of public universities to cope with the changed social and economic expectations get under the influence of many collective actors in their social environment" (Piber and Pietsch, 2006, p. 395).

Similarly, Dobija et al. (2019) experience a rational and symbolic use of performance measurement for Polish universities. Because "past studies have focused on the external use of PM for external accountability purposes [. . .]" (Dobija et al., 2019, p. 751), they integrate the perspective of internal actors using "[...] PM in response to exogenous pressures (coming from externally imposed regulations) and endogenous pressures (based on university responses or autonomous initiatives to assess their performance)" (Dobija et al., 2019).

For hybrid organizations, Agostino and Arnaboldi (2017) distinguish between a rational and a ritualistic use of performance measures. For some users of KPIs, they state that "they complied with the regulators' request to collect and report on the indicators but, in practice, they used their own set of organizational KPIs when making decisions" (Agostino and Arnaboldi, 2017, p. 414). Also, Teelken (2011) shows symbolic compliance in her comparative case study in three countries and 10 universities, whereas Conrath-Hargreaves and Wüstemann (2019) analyze the merely symbolic use of the business-logic in a single case study from Germany. Habersam et al. (2013) confirm these findings with reference to the KBS-implementation in Austria and finally speak about a "restricted validity of the measurement framework [the Austrian KBS]" (Habersam et al., 2013, p. 335). Hence, we can sum up, that there are considerable contributions in the literature highlighting the lack of managerial relevance of the KBS for universities. As a result, they state a symbolic use of the KBS to legitimize the universities to outside stakeholders with a rationality-façade.

For good reasons, the NPM-rationale has never been left uncriticized. Criticism referred to a more general level, such as the utilitarian "entrepreneurial spirit" (Osborne and Gaebler, 1992), new managerialism (Deem and Brehony, 2005) or a "control by numbers"-approach (Lynch, 2015). Moreover, there is critique referring to HES-developments especially, for instance, by Alexander (2000), Lynch (2015), Espeland and Sauder (2007, 2016) or Soh's (2017) critique of rankings (2017) or the demonstration by Nash (2019) on how neo-liberal NPM does not come, despite rhetoric of deregulation, with less bureaucratic impetus, but with what she describes as "marketizing bureaucracy" in parallel to "socializing bureaucracy."

Empirically-based literature offers many insights on the dysfunctional effects of "managerialism." Based on a large-scale survey questionnaire, Kallio and Kallio (2014) paint a "pessimistic picture" caused by a managerialist doctrine in Finnish universities. Anderson (2008) shows anxiety, demoralization, resistance and protest in 10 Australian universities. Teelken (2011) concludes an omnipresent stress and frustration in 10 universities in The Netherlands, Sweden and UK and Field (2015) refers to more and more disengaged academics feeling threatened, undermined and hurt by NPM-procedures. Agyemang and Broadbent (2015), highlight dysfunctional "colonizing" and coercive effects when "[...] organizations and/or their members [...] make some internal controls unnecessarily tighter than the external regulatory controls necessitate" (Agyemang and Broadbent, 2015, p. 1038). Aleksandrov (2020) shows in his case-study of a Russian technical university how accounting became a mediating device between academics and managers within the decade 
he observed. Our research question is formulated to cover the consequences of symbolic PMuse. The latter are not per se and necessarily dysfunctional. Enabling consequences may occur as well.

The term "enabling" refers to the conceptual framework of Adler and Borys (1996), a "[...] well-established theory in the accounting domain" (Lukka and Vinnari, 2014: 189; Strauss and Tessier, 2019). It allows for a systematic analysis of organizational processes via "[... .] two generic types of formalization - formalization designed to enable employees to master their tasks, and formalization designed to coerce effort and compliance from employees." (Adler and Borys, 1996, p. 62) Coercion is characterized by forcing members to stick to rules otherwise managers become suspicious, by punishment when deviation occurs, by asymmetric information and tight control procedures of supervisors. Forces to encourage coercion are based on asymmetries in power, knowledge, skills and rewards, a lack of participative structures to raise voice against asymmetries and a lack of reality check in competitive contexts. Enablement is characterized by using break-downs to learn and improve the system, and by providing feedback and contextual information. Forces to encourage enablement are seen by Adler and Borys (1996) with "cautious optimism" (Adler and Borys, 1996, p. 82). There is a broader tendency in culture in favor of participation, ideal speech situations to achieve consensus (with reference to Habermas) and dialogue between equal partners. In addition, competitive pressure and ongoing automation need better performance by participant involvement and sometimes changes in power relations. We will see in our case study that these "necessities" are not only relevant to for -profit production companies but for non-profit public universities as well.

Adler and Borys (1996) overcome the conventional juxtaposition of "high degree of formalization is mechanistic, and therefore, coercive per se" and "low degree of formalization is organic, and therefore, enabling per se." Instead, two other types are possible, namely, autocratic organizations and enabling bureaucracies. They see enabling bureaucracies as possible but ask as well for further research on how individuals perceive this development. In our case study, we analyze the role of perception when the dichotomy between coercive and enabling patterns is to be dissolved and replaced over time by a bundle of multi-faceted reactions and logics on an individual-, organizational- and field-level. This is especially relevant because the literature concentrates on the organizational level of single private sector organizations (Ahrens and Chapman, 2004, on restaurant chains; Jordan and Messner (2012), on a manufacturing company; the articles in the special section of Strauss and Tessier (2019). In the HES-context, we suggest to extend this focus toward a second layer i.e. the field level of state bureaucracy in which public universities are embedded. The relation with this field of regulatory and governing bodies is decisive.

Referring to necessary changes in power relations mentioned by Adler and Borys (1996), we interpret power not primarily as something members of the organization hold but as relational in nature emerging from the interaction. Fleming and Spicer (2014) call it an "endemic" part of organizations, "[. . . ] a resource to get things done through other people, to achieve certain goals that may be shared or contested" (Fleming and Spicer, 2014, p. 2). Power may occur as coercion, manipulation, domination and subjectification in, through, over and against organizations. This elaborated perspective is supported by Courpasson et al. (2012) and Courpasson and Clegg (2012), who suggest a stronger focus on resisting behaviors and how these behaviors are accommodated. To "accommodate" is to politically give space to temporary empowerment, trying to transform dissent and resistance into "productive elements" of governing organizations. "Productive" means to unleash creativity and trigger cognitive shifts by supporting surprising alternate interpretations as long as they challenge policy decisions up to a pre-defined extent but not beyond. 
QRAM 18,2
Courpasson et al. (2012) do neither negate common expressions of resistance like a strike as collective action nor what Fleming and Spicer (2003) describe as dysfunctional consequences of dysfunctional organizational patterns. However, they see resistance also "[...] as a legitimate working effort aimed at modifying the political status-quo" (Courpasson et al., 2012, p. 13). Systematizing resistance, Courpasson and Clegg (2012) focus on three forms of resistance: creative, appropriative and cooperative resistance (Courpasson and Clegg, 2012, p. 61, Table 1). Creative resistance is characterized by escaping and disidentifying, critique and cynicism; appropriative resistance strives to enter the managerial system and re-interpret the system's rules; cooperative resistance contests decisions and provokes crises of legitimacy to foster change. "Resistance under these conditions [...] is synonymous with tactics, which enable people to infuse existing structures of domination with unexpected ingredients [. . . ." (Courpasson and Clegg, 2012, p. 60) In our case study, we see diverse forms of resistance and tactics to make them productive.

In his exploration on how accounting begins, Power (2015) draws our attention toward the unfolding of a dynamics, which passes through different phases. Addressing the emergence of an impact accounting called ICS in the UK-HES he proposes a simple fourphase model of how the field level and the organizational level interact till an infrastructure and practices stabilize the accounting system. To systematically analyze what happens within an accounting event window when accounting begins, he distinguishes the phases of policy object formation and object elaboration followed by orchestrated activities till all culminates in stabilizing practices and infrastructure.

Policy object formation and object elaboration takes place at the field level primarily. The process of formation starts with problematization out of diverse perspectives, which have a certain disappointment in common, e.g. a lack of performance or sustainability or other diagnostic results asking for solution and improvement. This process may be reinforced by individuals as strong protagonists pushing for a new metrics and accounting representations as "[...] there is no new dream of performance improvement without a corresponding investment in accounting" (Power, 2015, p. 48).

Orchestrated activities, practice stabilization and infrastructure take place at the organizational level primarily. The ICS-template allows for sense-making, reduces complexity, makes an ambiguous concept such as impact manageable and auditable. Iterative elaboration of the ICS creates an apparatus which is more than a bundle of activities as soon as it becomes "materialized via the accretion of roles, rules, routines and governance structures" (Power, 2015, p. 50). In the end, it results in a regime (Hopwood (1987)).

For further research into what comes after the beginning when the regime is established Power (2015) proposes three directions. First, ICS may become in itself too complex not to become a policy disappointment. Disillusion may then trigger to restart the search for more promising solutions. The content of the infrastructure or regime becomes once more fragile. Second, subjectivisation is a non-deterministic process. It remains uncertain to which extent individuals adhere to the norms which accounting procedures demand or to the incentives provided or to which extent they resist. Therefore, subjectivisation may be understated when it comes to hard-wired permeation of the organization and overstated when its widespread diffusion is taken for granted. Third, infrastructures such as ICS foster an ex ante-view on outcomes as far as "[...] outcomes quickly become targets of management" (Power, 2015, p. 52, with reference to Espeland and Sauder (2007)) The anticipation of this management logic by researchers shortens time horizons when they feel obliged to demonstrate the impact of their research before the results are ready to be published. 
To contribute to these possible directions of further research, we adapt the four-phase concept of Power (2015) and stretch the time horizon beyond what he analyzed in the ICScase. This concept organizes our presentation of the empirics in Section 3. In our discussion section, we will focus especially on the phase after the calculative regime became a stabilized infrastructure for the first time. Because of our longitudinal research approach, we will be able to show the role of diverse perceptions, tactics and changes in power relations when the interactions between field level and organizational level unfolds over time with partly surprising consequences. Figure 1 illustrates the adapted concept.

The empirical material presented in Section 3 derives methodically from a longitudinal qualitative research approach analyzing HES-reforms in Austria. For more than a decade we have been accompanying the transformation of the Austrian HES (Habersam et al., 2013, 2018), focusing on accountingization-processes, the demystification of the intellectual capital-hype and its development into a so-called fourth stage (Secundo et al., 2016), as well as aspects of value creation and impact by public universities.

To better understand the consequences of the organizational changes in line with the new legal framework we conducted two series of qualitative interviews in 2011/2012 (12 interviews) and 2016/2017 (11 interviews):

- in total, 17 interviews in 4 different universities; involved were members of 2 comprehensive (CU) and 2 specialized universities (SU); we interviewed members on different hierarchical levels (rectorate, vice-rectorate, faculties and departments), researchers and administrative staff responsible for the new calculative regime, i.e. staff in administrative units such as controlling and/or quality management; deans and researchers with a background from natural sciences, social sciences, humanities and the arts;

- 4 interviews in the Ministry with responsible people for the development of the calculative regime; and

- 2 in other institutions of the Austrian HES to get expertise from a different angle, i.e. the Austrian Academy of Sciences (ÖAW) and the consulting company involved in a report analyzing effects of the new calculative regime.

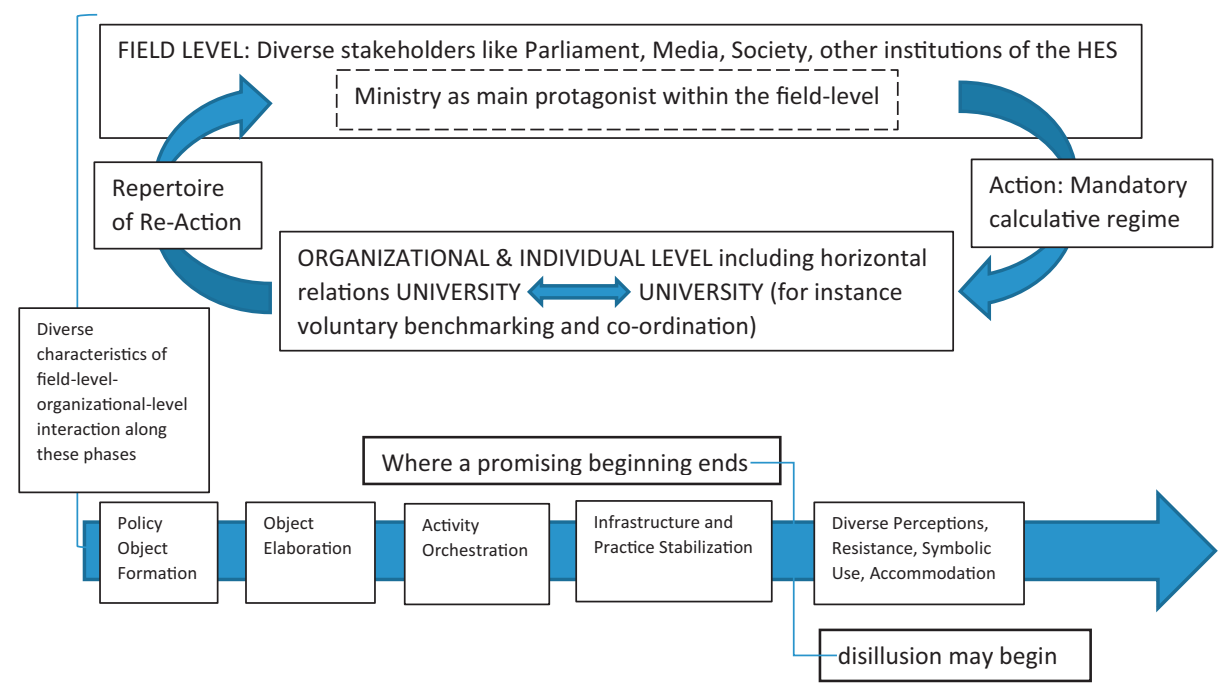

Figure 1. Multi-phase-concept to analyze unfolding dynamics in calculative regime implementation 
QRAM

18,2
In the 2 series of interviews, we tried as far as possible to talk with the same protagonists twice. The interviews took between 45 minutes and 2 hours, were semi-structured and addressed following topics: functionality/dysfunctionality of the new calculative regime, its relevance for decision-making, workload, possible (non-)use, implications, if an improvement of the KBS is possible or not, if not how an alternative could look like. The interviews were partly very intense and open with a broad range of emotions and attitudes such as anger, engaged resistance, willingness to improve, pragmatism, disappointment, resignation or ignorance.

We recorded and transcribed the interviews, and then clustered quotes into main topics and corresponding insights. Main topics could be named by different stakeholders (e.g. on workload or why it is necessary to resist an abstract framework). Controversially discussed topics highlighted dissent between stakeholders on the organizational level or field level. After re-reading, the clusters were once more refined and we compared the clustering and interpretations of the first round with second-round insights. In fact, every interview was read several times, which is why we did not use supportive programs such as NVivo or similar products. We became very familiar with the materials' content over time as a team. Because we act as a team of three researchers from two different countries, an investigator triangulation became possible over the years (Yin, 1994).

Furthermore, we matched the interview-material with internal documents from the Ministry, i.e. a systematic workflow on data collected in the HES and its relevant sources, and a short summary of the report of the consulting company (the report itself was not made available). In addition, we consulted documents like:

- The public university-reports (in German "Universitätsbericht") because the Ministry has to inform the Parliament on the development of the public universities every three years; the current one is from 2017 (Universitätsbericht, 2017).

- Apart from the University Act itself, the legal documents in terms of the decrees (Wissensbilanzverordnung" in German, abbreviated "WBV" in the references below) on how to operate the calculative regime, especially the KBS as central calculative technology since 2006. The current decree is from 2019.

- Uni-data as the relevant database to provide statistics of the Austrian HES to the general public in different formats.

- The reports of the Austrian court of audit regularly published on HES-institutions and specific programs or activities.

- A short video [1] of the Ministry promoting the KBS (in German "Wissensbilanz") as an aggregated, systematic and mainly standardized representation of the universities' Intellectual Capital, based on objectified data and giving a "panoramic view" on science and society's progress.

In 2018 and 2019, 2 of our research team were invited to take part in workshops of the Ministry on de-bureaucratizing the HES. The insights from these workshops complement our perspective on the interacting processes of organizational change and new calculative regimes from a more informal point of view.

When talking to our interview partners, we were interested in their individual retrospectives and reflections on emerging practices. Being "retrospective" allows for different methodological assumptions as Cox and Hassard (2007) point out. We take an interpretive and re-presenting constructivist position when we act as "bricoleurs" of diverse narrations. To us, validity is more a consequence of plausible reasoning within a specific context. The narration itself problematizes and reflects on social, political, 
organizational, ethical contexts, but the researcher her/himself is embedded in these contexts, especially when researching into bureaucratic organizations such as public universities we are part of.

\section{Austrian public universities}

\section{The case}

The description of the case starts with the political impetus to reform the Austrian HES and is organized along Powers' four-phase template of policy formation, elaboration, activity orchestration and infrastructure/practices of stabilization. The Austrian University Act 2002 (UG, 2002), in combination with a first KBS-decree with 53 indicators in 2006 established a first infrastructure. In this early phase, most activities centered around the field level while activities at the organizational and individual level were dominating the scene in the period after the beginning was set by decree. Our longitudinal perspective shows which kind of activities emerged and how the relationship between field level and organizational level developed over time. What emerged is a story of a calculative regime in the making triggered by diverse perceptions, dissent, resistance, changes in power relations, symbolic use as tactics and with enabling consequences.

\subsection{Policy is setting the scene}

The beginning of the new calculative regime installed was policy-driven. One of the most determined protagonists of the Austrian University Act in 2002 (UG, 2002) defined the political goal as transforming public universities into "enterprise-like entities" (Höllinger, 2004). The new legal framework changed the relation between the state (represented by the Ministry) and the public university profoundly [2]. The main player on the field level withdrew from operations and became a kind of "remote controller" as described above. The Ministry's focus should be on strategic governance by transferring tasks, decision-making competencies and responsibility to the autonomous public university. On the organizational level the management structure of public universities was changed toward more enterpriselike structures. Their management now consists of the rectorate, responsible for the decision-making on operations; the Board of Trustees (in German "Universitätsrat") responsible for strategic decisions, e.g. approving the development plan and first drafts of performance agreements and the organizational structure, electing the rectorate and supervising internal budgeting; finally the senate, responsible for academic codetermination in teaching affairs, curricula, academic titles, etc.

Although we focus on the Ministry as main protagonist and its impetus, activities and decisions on field level, the field itself consists of more: relations to other organizations and institutions such as the Parliament, for instance, or the media and a certain Zeitgeist of measurement by numbers and control. Politicians look more at data and listen less to narratives, which was the other way around in former times (ÖAW).

The public in general, i.e. society, is a differentiated somehow vague part of the field. Stakeholders such as citizens, students, private or public companies, various funding organizations and political institutions are represented via political processes on regional and federal level. They have different interests, goals, powerbases and structural opportunities to raise their voices. Politicians are confronted with floating majorities and shifting power relations in Parliament when supporting idea(l)s of educational policies. It is not always clear who is the addressee of performance in education, research and third mission. To inform the public, an abstract, standardized format on a highly aggregated level of governing by numbers seems appropriate to demonstrate legitimation and accountability. Especially the political parties in opposition when the University Act was passed, asked strongly for "accountability" to balance the growing autonomy of public universities. The 
QRAM

18,2

Ministry has to inform the Parliament on the development of the public universities every three years but also interpellations of the Parliament are now more common and have to be answered by the Ministry. According to some of our interview partners [. . . ] to develop a new system of accountability [...]-economically, [.. .] in terms of performance-[...] there was also the idea of a KBS to report the development of knowledge at the university (Senior Officiall Ministry).

Under pressure to offer transparency and legitimation toward the public in general, and especially toward the Parliament, the Ministry finds itself in an ambiguous situation. It has to assure accountability it has to supervise, but it also depends on the universities' data and their substantial explanations to negotiate performance contracts. Consequently, the Ministry initially pushed the KBS not to be cut-off from data: [...] we have the KBSinformation only (Senior Official/Ministry). Right from the beginning, the calculative regime as a process has been organized as follows: within a rolling forecast and planning approach, every public university prepares a detailed development plan for three years and a less detailed plan up to six years. Performance contracts and a global budget are based on it, accompanied by monitoring-talks between the Ministry and the individual university twice a year. The PMM-system was installed to control the degree of achieving the aims defined in so-called "performance contracts" between the Ministry and the individual university. These contracts are the decisive link between the Ministry and the rectorate, as well as the board of trustees of the individual university. Performance contracts and the KBS are the new calculative regime as a package. Its dominant character results from being mandatory according to the Austrian University Act, which is still unique in the European higher education area. The calculative regime is to the Ministry of particular importance when governing the Austrian HES because it provides the basis for negotiating the development plan and the performance contracts between the Ministry and the public universities (Universitätsbericht, 2017). Furthermore, it correlates with the financial framework conditions of public universities in Austria defined by the Ministry of Finance.

\subsection{The knowledge balance sheet as first stage infrastructure}

In its origin, the KBS refers to the MERITUM-project's intellectual capital taxonomy of performance measurement defining its structure as human, relational and structural capital (Piber and Pietsch, 2006). At present, the KBS combines a narrative performance report, the set of performance indicators, and the report on the performance agreements implemented already. Table 1 shows its 24 performance measures. Each university may add additional performance measures but in accordance with the Ministry. Universities need to hand in a full version of the narrative performance report in year one but can hand in a short version in year two and three.

Apart from presenting a new calculative technology in terms of structure, the question is how it is perceived and enacted by the stakeholders involved.

\subsection{After the beginning: dissent and resistance}

From a field-level's perspective, a given infrastructure by decree and stabilized practices between the Ministry and the individual university should have resulted in a successful implementation of a "governing by numbers at a distance"-approach. Thereafter only marginal adaptation should have been necessary. This was, however, illusionary because of specific activities on the organizational and individual level.

Public universities are very diverse in focus/specialization, size and strategies chosen and are predominantly managed by academics not by professional managers. The academic 


\begin{tabular}{l} 
Intellectual capital \\
\hline Human capital \\
Personnel \\
Number of appointments \\
Female quota in collective boards \\
Wage-difference between male \\
and female personnel \\
Representation of women in \\
appointment procedures
\end{tabular}

\section{Relational capital}

Number of scientific personnel with a stay abroad (visiting researchers)

\section{Structural capital}

Income from research and development projects (in €) Investment in infrastructure in the area of research and development (in €)
Core processes. . .

...of study programs and advanced training

Number of professors (fulltime

equivalents)

Number of study programs

Success quota of regular students

Number of applicants for study programs with specific entrance requirements

Number of students

Number of study enrolments (active in exams; bachelor, master and diploma studies)

Number of study programs enrolled in by regular students Number of regular students taking part in international mobility programs (outgoing)

Number of regular students taking part in international mobility programs (incoming)

$$
\begin{aligned}
& \text {...of research and development } \\
& \text { including the development of the } \\
& \text { arts } \\
& \text { Doctoral students employed by the } \\
& \text { university }
\end{aligned}
$$

Output and impact of the core processes...

\section{Austrian public universities} advanced training

Number of studies accomplished Number of studies accomplished within the timeframe tolerated Number of studies accomplished including a study-abroad period within an international mobility program

\section{...concerning research and development including the development of the arts} Number of publications Number of scientific presentations Number of patent applications, granted patents, exploitations of spin-offs, license, options and selling contracts
Table 1. Performance indicators in the KBS

staff involved in managerial tasks has different academic backgrounds and scientific cultures. This diversity results in ambiguity. To deal with it when governing public universities seems to be a conditio sine qua non. The organizational structure decided for in the University Act of 2002 led to a rectorate which became a more powerful governance institution compared to the former collegial governance. However, these changes, combined with a new calculative regime still provoke opposing judgments articulated by the organizational and individual field.

Two main issues can be identified where dissent between field level (here we focus on the Ministry) and the organizational and individual level becomes obvious:

(1) How is the "governing by numbers at a distance"-approach represented by the new calculative regime including the KBS perceived?

(2) How is the impact of the new calculative regime and the KBS especially on managing public universities judged?

Concerning the first aspect, perception, it is important to notice that the organizational and individual level of public universities is not homogeneous. CU and SU differ from another and even within the individual universities, the approach to govern public universities by numbers at a distance is perceived differently. It depends which scientific traditions and cultures play a significant role: 


\section{QRAM} 18,2

I think the faculties handle numbers different. That's just a personal observation. I have the feeling that for example natural sciences just take the numbers and welcome them, whereas the humanities are more critical, they [.. . ] are not working too much with numbers (KBS-Office/CU).

Diverse types of SU may offer the same dichotomy, i.e. [...] in the field of art there is no tradition of counting (QM-KBS/SU), whereas technical universities may:

[...] think much stronger in competitive categories, judging the KBS positively because it gives them the opportunity to show their capabilities and achievements (Management consultant).

The critique of a "governing by numbers at a distance"-approach is attached to the word "distance," i.e. not being able or willing to understand "the other." One dean described his unsuccessful attempt to convince the rector of the value of philosophy: eventually I understood [...] such things he does not understand because it is not transferable into numbers. S/he asked:

What does management of a comprehensive university mean if there are up to three different scientific cultures and $[\ldots]$ hard facts come from a culture, that is not humanities, but from a culture driven by natural sciences? (Dean/CU/T)

To "hunt" only for publications (see the KBS-indicator "number of publications") or grants (see the KBS-indicator "income from research and development projects (in €)") may not be appropriate for every scientific discipline. Especially, if disciplines have less access to grants for structural or cultural reasons. For professional academics in the humanities writing influential books (in German) but fewer articles in internationally refereed journals with a high impact factor, the KBS and its effects may threaten their professional selfunderstanding. They interpret standardization and governing by numbers as dysfunctional coerciveness, undermining reputation as main reason to engage in scientific activity.

A more radical critique judges the attempts to represent quality by quantities as unnecessary, a-historic and misleading. A number or quantity in itself (see, for instance, the KBS-indicator "number of scientific presentations") is not demonstrating or even assuring quality:

For purposes in terms of advancement of quality it is not necessary. There are many other mechanisms. There is a system of quality assurance, which is the scientific community. A system that does not react very quickly, but it is a system which worked for hundreds of years; to say, that the university would not be able to produce quality without a quality assurance system implemented on government level is ridiculous if you look back to the history of science (Rector/SU).

Changing perspective toward the field-level, the Ministry perceives the approach of governing by numbers as functional in two ways: First, data clearing and plausibility checks developed with the calculative regime strengthened the Ministry's position in budgetary negotiations, performance agreements and accompanying talks over time by an extended benchmarking capacity. Second, from the Ministry's perspective, public universities should not only bemoan being benchmarked by the Ministry but use the KBS for internal managerial control purposes. Relating to impact, very different judgments occur. The Ministry describes the KBS as useful for internal managerial control processes and valid source of highly aggregated standardized data. In contrast, from a public university's perspective, the KBS did not become prominent in internal managerial control procedures down the hierarchical line. Nor did it become the public universities' preferred calculative technology for longitudinal self-benchmarking and -reflection (Vice-Rector for Student Affairs and Teaching/CU). The lack of diffusion is argued by the public universities as a consequence of fundamental shortcomings in communicating "sense." For a tool celebrating 

when the [...] declaration of the political will is not visible (Vice-Rector for Student Affairs and Teaching/CU). To discuss and make sense of a KBS-indicator, for instance, "number of studies accomplished within the timeframe tolerated" shows this necessity:

For example, graduates and study time consumed. Students study quickly and are very focused, or they study parallel to their jobs, and they need longer. There is a statement missing about the aspects which are positive or negative (Admin KBS/SU).

Without a transparent role-making by the Ministry on strategic goals and criteria for judgments on an operational level a [...] lot of energy is devoted to sideshows, to technological management and less energy to [. . . systematic management (Admin KBS/SU).

\subsection{Tactical behaviors to cope with dissent: resistance and symbolic use}

Dissent results from diverse perceptions and judgments on impact, and consequently, diverse tactics emerge to cope with the unavoidable, i.e. the mandatory character of the calculative regime established by decree in 2006. There is tactical behavior as "open resistance for persuasion" to change the infrastructure for the SU at least, although the arguments were used by other organizations and individuals as well with an impetus of improvement. "Symbolic use" is another tactic, less opposing but using open spaces for maneuver to maintain a high degree of autonomy in how to manage performance in parallel.

"Open resistance for persuasion" has some interesting facets and consequences. Some public universities resisted to benchmarking by the Ministry over a longer period of time. Although benchmarking was a trigger there were some fundamental arguments backing their resistance. Resistance emerged especially in between 2006 and 2009 because of the ostentatious attitude of the dominant governing by numbers approach to represent the value of the organization (for society) as a whole. This attitude was fundamentally called in question and judged as ignorant. This does not mean that resistance, in this case, was driven by a no-numbers-at-all-approach. On the contrary, it was asked for structural changes of the existing KBS to make sure qualitative aspects are represented adequately:

[...] after three years the ministry also began to understand that they cannot make use of reports to compare the six universities of arts when every university says this is not relevant for us; and we have now the possibility to report, in a written way, but not accounting for our activities, so we can add a text with relevant activities in different fields [. . . ] I think this is a far more sensible approach, and also evaluate reporting in a qualitative way, which is very much more reasonable in the field of arts' (QM-KBS/SU).

The culture of the scientific community matters when it comes to resistance. Because the arguments of the opposers provoked a broader response within the organizational level, the KBS-indicators were reduced from 53 to 26 in the second decree on KBS-reporting in 2010.

Sometimes, resistant behavior leads to involving a third party. In our case, the Ministry engaged an internationally renowned consulting company to analyze the KBS-use by public universities and to reveal critical aspects. The results focused on strategic and operational recommendations. To improve the KBS, public universities asked for a transparent HES-strategy, a defined role of the KBS, fewer indicators or qualitatively improved ones, less double work, a narrative part with minimal requirements and more space to present their diversity. The Ministry reacted partly on some aspects, primarily operational ones. For instance, the number of indicators of the current KBS of 2017 is down by two, the ways to calculate indicators are discussed on a broader basis, and the narrative part causes less work now. 
QRAM 18,2
However, the tactics of persuasion turned into enabling consequences as well when public universities and the Ministry started to push toward a communicative culture and dealt with ambiguities by co-operating more strongly with the universities' conference (in German "Universitätenkonferenz", abbreviated UNIKO). The aim is to consider [...] the opinion of the university more profoundly (Management consultant) and to strive for a more [...] consensus-oriented behavior. Every change of decree will be aligned with the universities (KBS-Official/Ministry). The public universities and the Ministry adjust incorrect figures effectively beforehand by embedding possible dissent into "talk." Quarreling about "right" or "wrong" dat has substantially diminished over the years.

"Symbolic use" maintains a façade to satisfy external requirements without further identification. It is a pragmatic behavior, sometimes with a touch of "resignation." Because of new calculative regime installed public universities established processes and hired administrative staff. Out of a Dean's perspective: what I observe [...] is an increasing bureaucratization of administrative processes, centralized [...], which drowns a lot of creativity (Dean/CU/T). For professional administrators in the universities' staff who often come from a management background, the calculative regime causes ambivalent reactions. On the one hand, this tool [.. . ] turned out to grow and grow (Rector/SU). On the other hand, it serves the [...] interest of all the people working on that (QM-KBS/SU). The KBS became business as usual, basically a ritual. Our staff is professional and routinized in preparing the data and it is simply to deliver (Vice-Rector for Student Affairs and Teaching/CU). Public universities have learned to understand that the KBS will remain a relevant governance tool for the Ministry, which will not be abandoned. Therefore, being in permanent dissent with the Ministry becomes exhausting. Over the years you cease from raising the question of meaning again and again (Admin KBS/SU). There are traces of "cynicism" and signs of less identification with the own organization many people do not take the KBS seriously. It is a bunch of data [...] enforced by decree, [...] for most it is not more (Admin KBS/CU). Although the new calculative technology is installed, its limited impact down the hierarchical line is obvious. I never took an indicator directly from the KBS. [...] It is an input-only-system from our perspective [...] with much effort (Dean/CU). "Input-onlysystem" means faculties deliver data but do not profit from it for their own governance. This is not an occasional opinion: in all my six talks, there was no university, which said, they would need or really use the KBS. For the ministry the cost-benefit-ratio is definitely better (Management consultant). Reasons for dissatisfaction are manifold, for instance, when indicators like third-party-funding are calculated three times differently - for the KBS, for internal budgeting and for the profit and loss statement. Others are criticizing timeconsuming double work when informing the general public by public relations and simplified statistics, which is not the data-format produced for the KBS. Some public universities see the narrative part of the KBS as an unnecessary burden preferably to be abandoned (Vice-Rector for Student Affairs and Teaching/CU). Most dissatisfying, however, is how few managerial consequences are drawn from all the data produced because [...] there is much more data to consume, than time to interpret the data (Vice-Rector for Student Affairs and Teaching/CU).

However, this describes only one facet of symbolic use. Symbolic use opens up spaces for maneuver, which are filled partly by enabling consequences as well. For example performance measurement leads to performance management, even if the KBS is not used for internal managerial processes within public universities. This, however, does not mean that PMM does not take place. To co-ordinate what is useful within the infrastructure given, a parallel organization on the organizational level emerged, which is organized horizontally: a network built between public universities. Based on mutual trust some universities 
voluntarily benchmark each other on selected indicators (Admin KBS/CU and Dean/CU/T). This allows for improvement:

For me benchmarking is ok, because I see what they are doing at university A, [...]. It is interesting, here we have too many drop-outs, $\mathrm{A}$ is a little bit better. What are they doing in this way? It is an incentive for learning (Vice-Rector for Student Affairs and Teaching/CU).

All tactical behaviors with all their facets and nuances exist in parallel, as a kind of repertoire to accommodate the effects of new calculative regimes which become an infrastructure and are stabilized through practices. However, these infrastructures are challenged and disruption occurs triggered by resistance and symbolic use. The unintended consequences are not only dysfunctional but as well enabling. Having a closer look at dissent, resistance and tactical behaviors something else becomes even more visible power.

\subsection{Changes in power relations}

When the University Act changed the organizational setting one and a half decades ago, there was a "sigh" in the Ministry of the early days: "both sides feel weak" (Habersam et al., 2013: 334). Today, nobody of the stakeholders involved would support this narrative. Probably, a title could be: "both sides use the chances of a communicative culture in favor of a more consensus-oriented behavior." But what happened in between the two "narratives"?

Due to the growing autonomy universities decide more and more operational and strategic issues on their own. However, the Ministry is still the primary funding body of public universities, which underlines its role in governing the Austrian HES. Finally, they give the money; of course, when they say they want to have something in the Leistungsvereinbarung [performance contract; the authors], you put it in (Budgeting and Controlling/CU). However, the use of "hard" power (i.e. power somebody holds who decides budgets) changed in style over time. In the beginning, the Ministry was confronted with political pressures to present to the Parliament transparent performance agreements with the public universities. It had to deal with a succession of ministers and changing political aims for the Austrian HES:

A new minister, some new ideas and the next accompanying talk is of course full of these 2 or 3 new ideas. And in my opinion it is hard for a university to react on this kind of strategic change, because last year this one and next year another one. (Member of the Ministry)

While negotiating development plans and budgets in the early years of the new calculative regime public universities were confronted with the following:

[...] we had, I think, four rounds of negotiations, and the ministry, during the first three rounds [... . said to every single thing, with some exceptions, "very good", "great idea" and "we like it", "we should do it"; and afterwards, in the fourth round concerning money they said we give you the half of what you want' (QM-KBS/SU).

Experiences of "unpredictability" led to a more robust relational attitude and behavior. On both levels, protagonists tried to better understand the circumstances "the other" had to face. The public universities had to accept that for the Ministry [...] the KBS is [...] an important source of information, to fulfil its responsibility, its supervising function. So, you cannot abandon it [...] (Admin KBS/SU). It will continue to govern via the new calculative regime and negotiate budgets on a far more sophisticated data base, which allows for comparison and benchmarking. In addition, the Ministry recognized clearly: if universities work to rule when delivering data to the Ministry, there will be no spirit and purpose in the end (KBS-Official/Ministry). Both started to invest time in communication because [...] in the 
QRAM 18,2

end it is very much how you can talk to somebody: negotiation and relations (Budgeting and Controlling/CU). Accompanying talks to the performance contracts twice a year give public universities the chance to better anticipate what may become a politically important KBSindicator (for instance, gender pay-gap, third-party funding percentage or how many students accomplish their studies on time). It gives them also the chance to present alternate opinions and proposals of improvement to the Ministry. The Ministry uses the chance to have first-hand information in discussions in a comparatively informal context. This demonstrates the relational nature of power. It exists as a coercive force of command and through an enabling acknowledgment by others. A new balance of power emerged between the organizational and the field-level, in the process of political dealing between university and ministry (Rector/SU).

In addition, in 2018, the Ministry initiated a workshop series to explore options of debureaucratizing the HES with members of the Ministry, public universities and other experts. It is as if changed power relations marked-out some common ground: only idealists would ask for more metrics at the core of the KBS as calculative technology. Debureaucratization as a target was, on the one hand, backed by the results of a consulting project already mentioned above. On the other hand, journalists of relevant national media bemoaned the highly complex reporting framework and its workload for universities (Bayrhammer and Grancy, 2018). As a result, there are now some options to reduce the operative workload for universities, to curb the generation of data and to synergize the various reporting duties. However, what consequences result from these workshops for the calculative regime on both levels is still an open question.

\section{Discussion and contribution to the literature}

In line with the research question, we will discuss the implementation and the consequences of the new calculative regime over time. After policy has set the scene and the mandatory KBS became the backbone of the calculative regime as an infrastructure established by decree, diverse perceptions gave way to dissent and tactical behaviors. However, it needed changes in power relations as well to allow for the expression of dissent and diverse tactics to fill the new space for maneuver opened-up in the ongoing interactions between field level and organizational level. Focusing especially on the phase after the calculative regime became a stabilized infrastructure for the first time, we have a closer look at what unfolds over time and we find partly surprising consequences. A first insight from the empirical material presented is the decisive role of "perception."

\subsection{The role of perception}

Unsurprisingly, perceptions differ from stakeholder to stakeholder. What is of importance are the consequences emerging in the interactions of the field and organizational level and its dynamics over time.

For the Ministry as the main player on the field level, the KBS is an adequate tool for informing the Parliament every three years:

The KBS overarches a retrospective overview what happened at the university in all relevant areas - teaching, research, societal targets, cooperation, and internationality. And if you put together the figures from all universities, then you really have a good view what is going on in the institutions. Hence, I would definitely say that this panoramic view is possible with the KBS. (One of the KBS-Officials of the Ministry)

Although the taxpayer wants to know if the money is used in an effective way (. . .) but would not read the KBS (Admin KBS/SU) the Parliament seems to have a different perception, at 
least from time to time. Its interpellations demonstrate some dissatisfaction with the information offered by an aggregated, standardized format. Otherwise, interpellations would not grow in number. It may be a sign of a calculative regime becoming too abstract and de-contextualized. Interpellations can be interpreted as an attempt to re-gain detailed and re-contextualized knowledge for decision-making in complex contexts. To answer interpellations results in extra workload down the line when universities have to collect specific data the KBS does not offer. This is one aspect national media bemoaned to create a certain awareness for processes of accountability (Bayrhammer and Grancy, 2018).

On the organizational and individual level, perceptions are different from the positive interpretation of a comprehensive, panoramic format to serve informational interests sufficiently. An initial critique referred to the absence of qualitative description and the dominance of quantities. This was resolved later on by allowing for text in addition to numbers only. As this only happened after three years of arguing, timewise this definitely can be placed after the calculative regime became an infrastructure for the first time (see Figure 1). The perception of distance as critical aspect when decisions are based on aggregated and abstract figures is described in the case. The feeling of being represented inappropriately when it comes to the recognition and appreciation of the diversity of public universities and the complexity of tasks with their diverse performance logics (research, teaching and third mission) is present from the beginning and part of the disillusion following. Skepticism regarding the quality of representation by an abstract compilation is an important perception. It can be linked to critique we know from literature. The idea is to inform diverse stakeholders by referring to the KBS: enterprises might be interested in R\&D-projects, exploitation of spin-offs, patents and grants. Students may be interested in the ratio professors/students, success quotas of study programs or the number of $\mathrm{PhD}$ contracts offered by the university in case they aim at a scientific career. Out of a societal perspective, female quotas or gender wage gaps may be relevant. The state and policy actors are probably interested in how well the "three E's" (economy, efficiency and effectiveness) are achieved, and therefore, may have a look at studies accomplished within the time frame tolerated or at numbers of students in international mobility programs. Finally, some of the academic oligarchy may be interested in the number of scientific publications and investments in infrastructure and personnel. However, inherent to an aggregated construct of compilation such as the KBS is the idea to optimize the separate indicators to achieve maximum outcome. This is taken for granted in an economic rationale. However, the aspects of dysfunctional distance and de-contextualization tell us that this rationale is probably misleading when representing impact means to integrate diverse performance logics. This is not a merely additive process (Johanson and Skoog, 2015).

In addition, public universities and their academic oligarchy are themselves heterogeneous in their perceptions. Increasing bureaucratization drowns creativity (Dean/ $\mathrm{CU} / \mathrm{T}$ ) and coercive use of managerial control provokes dissent and resistance - but not from everyone because of different backgrounds of scientific culture. While natural sciences faculties may welcome numbers or are at least are more tolerant toward a formal governance approach at a distance, humanities and arts are at best sceptic, mostly adverse. This happens especially when administrators or managers are ignorant and not willing to hear their arguments and feel their fears, such as losing reputation and professionalism. The implementation of a calculative regime becomes a matter of very personal emotional experiences like anger, fear, dislike and mistrust. This describes individual and situational attributes Adler and Borys (1996) proposed to further research when trying to better understand what may foster enabling aspects of organizations in transition. As far as diverse perceptions result in dissent we can observe diverse tactics with consequences for 
QRAM 18,2

what Power (2015) referred to as "subjectivisation." In our case, the issue of benchmarking is a noticeable first point of reference.

\subsection{The role of tactics and power}

Benchmarking is more than a neutral calculative accounting technique, it is a political procedure. The following quote shows some important aspects: [...] after three years the ministry also began to understand that they cannot make use of reports to compare the six universities of arts when every university says this is not relevant for us; and we have now the possibility to report, in a written way, but not accounting for our activities, so we can add a text with relevant activities in different fields [...]. I think this is a far more sensible approach and also evaluate reporting in a qualitative way, which is very much more reasonable in the field of arts (QM-KBS/SU). There is a remarkably intense resistance over a three years period and guided by an impetus of persuasion. It is nourished by the culture of the discipline (the arts) and by the perception of dysfunctional consequences of a distant governing by numbers approach. Doubting the adequacy of the numbers-approach to represent qualities by quantities unites all six universities of art and some other (members of) scientific cultures such as humanities, for instance, in CU. This alternate perception triggers efforts to make sure not to compare the incomparable, i.e. "text" to represent quality issues instead of accounting figures only. This is judged as a more sensitive and reasonable approach. It is context-specific but remains within the format of formalized reporting and accountability.

We describe this first tactical behavior identified as "open resistance for persuasion." Its idea was to change - not to abandon - the KBS-infrastructure (for SU) but this idea became more widespread. To better understand this dynamic we need a conceptual frame on power and changes in power relations. When the infrastructure was set by decree at the beginning both sides felt weak. This was a time when public universities were no autonomous players on the organizational level. Over time a necessity to establish a new balance of power between the organizational level and the field level emerged. Although the Ministry is still the primary funding body of public universities and holds the power over budget decisions, the use of power has changed over time. In the beginning, the experiences of "unpredictability" in performance contract negotiations described in the case led to a more robust attitude of resistance. Open resistance for persuasion uses new spaces of maneuver on the organizational level to argue in favor of changes in the infrastructure. Because the organizational level knows that the field level will not abandon the KBS, public universities and individual protagonists on the organizational level have to decide on their practices of resistance.

To better understand the repertoire of resistance we refer to Courpasson and Clegg (2012), who distinguish three forms, namely, creative, appropriative and cooperative resistance (Courpasson and Clegg, 2012). Creative resistance is characterized by escaping and dis-identifying, critique and cynicism, but it may end up in a zone of indifference. Appropriative resistance strives to enter the managerial system and re-interpret the system's rules whereas cooperative resistance goes further, contests decisions and provokes crises of legitimacy to foster change. By having a closer look at the issue of benchmarking and the tactics of open resistance for persuasion we see cooperative resistance at work. "Resistance under these conditions [...] is synonymous with tactics, which enable people to infuse existing structures of domination with unexpected ingredients [.. .]" (Courpasson and Clegg, 2012, p. 60).

One of these "unexpected ingredients" we can present in our case is the unintended enabling consequence of profound changes in the practices of communication. Both levels 
started to invest time in communication and quality of relation. Concerning the interaction of field and organizational level, the Ministry and the public universities adjust incorrect figures effectively beforehand. Often changes of the KBS are aligned before they become mandatory by decree. Accompanying talks to the performance contracts twice a year give public universities the chance to better anticipate trends in KBS-indicator changes (for instance, gender pay-gap, third-party funding percentage or how many students accomplish their studies on time). The organizational level gets the chance to present alternate perceptions whereas the field level (Ministry) gets first-hand information in a less formal context. The new balance of power is represented by these processes of communication. In addition, the Ministry's de-bureaucratization workshops initiated in 2018 marked-out some common ground, i.e. not to invest in more of metrics but in communication about metrics and what consequences to draw from these.

To describe this process as "accommodation" (Courpasson and Clegg, 2012) stresses the fact that the endemic nature of power in organizations (Fleming and Spicer, 2014) is cultivated by new processes of communication during appropriative (re-interpreting rules) and cooperative resistance. Part of this accommodating process enacted is the involvement of so-called "third parties." An unsolicited involvement happened when two journalists bemoaned the highly complex reporting framework and its workload for universities in 2018. A solicited involvement took place in 2015, when the Ministry engaged an internationally renowned consulting company to analyze and reveal critical aspects of the KBS in use. The effect of the latter was not to invest in more metrics but in fewer or qualitatively improved ones. Via the consulting-process public universities became more demanding, claimed to need a transparent HES-strategy, a defined role of the KBS, less double work, a narrative part with minimal requirements and more space to present diversity. Although these claims were taken into account selectively by the Ministry it shows some power of cooperative resistance.

The empirical evidence and analysis of the interwoven nature of dissent, resistance and power, the dynamics of a new balance of power emerging over time, furthermore contributes to Power's (2015) proposal to research into the new fragility of the infrastructure after the beginning has taken place. He sees a certain chance that a calculative regime becomes too complex and therefore will turn into a policy disappointment. In our case, disillusion created a new fragility of the infrastructure, for example, when the number of KBS-indicators was reduced from 53 to 26 by 2010 and then to 24 indicators. To thematize the role of power and changes in power relations allows for a better understanding of the dynamics of change from coercive stabilization (legal framework) to destabilizing and at the same time stabilizing resistance with periods of fragility embedded. It is theoretically and practically fruitful to combine the perspectives of dissent, resistance and power with a specific focus on enabling consequences. It substantially enriches the four-phase model of calculative regimes installed by focusing on aspects "[...] closely knit together in complex and often contradictory ways" (Fleming and Spicer, 2008, p. 304) but yet less acknowledged.

The second one of the "unexpected ingredients" mentioned above is the tactical behavior of "symbolic use," resulting also in unintended enabling effects. Vertically analyzed, the empirical material shows a low degree of diffusion down the hierarchical line because at Deans' levels, KBS-indicators are not used for decision-making. While the Ministry assesses the KBS as useful for internal managerial control processes and as a valid source for being benchmarked by the Ministry, public universities' state primarily non-use of the KBS and a low degree of diffusion. Universities simultaneously established their own calculative technologies. This is in line with the findings of Dobija et al. (2019) and Agostino and Arnaboldi (2017). Symbolic use means to serve ritualistically a purpose you do not 
QRAM 18,2

necessarily identify with - and doing something different in parallel. The managerial notion "what gets measured gets managed" (Catasus et al., 2007) is to judge carefully when symbolic use becomes a tactical behavior. In this case, the focus should be on what measures are of real importance, and what measures are symbolically provided but of less or even no importance to decision-makers on the organizational level. By these insights we complement the work of Piber and Pietsch (2006), who emphasized that the implementation of the KBS triggers changes in the symbolic context. Only in the long run we can as well see changes in the technical context and a use of the data. The longitudinal approach shows how the mainly legitimation-oriented calculative regime smoothly triggers more and more enabling performance management practices, as well as changes in the infrastructure itself. In the theoretical lens of a new institutional approach, we can understand this as an institutional isomorphism on a national level, as the consequences of tactical behaviors refer to all universities similarly.

Horizontally analyzed (Hopwood, 1996), on the organizational level mutual relations become manifest in a much closer network of public universities. It enables public universities horizontally to better exchange on calculative technologies and to learn instead of staying isolated in dissent. Voluntary benchmarking between public universities is a matter of mutual trust. In between public universities, it becomes a productive element to trigger learning processes when understanding why others, for instance, have less drop-outs and what it tells the individual university for its specific management situation. It is a kind of reality check in its co-operative attitude of learning, improving the system, providing feedback and contextual information. The organizational level became an important sub-set of power in the relation between field level and organizational level.

This shift toward an understanding of public universities as bureaucracies with enabling characteristics (Adler and Borys, 1996) deriving from tactical behavior in contexts of calculative regimes should not be understood as if there were no dysfunctionalities to face. From our empirical material, we can support insights from Anderson (2008), who shows anxiety, demoralization, resistance and protest, and Field (2015), who refers to more and more disengaged academics feeling threatened, undermined and hurt by NPM-procedures. The motivation to criticize a "governing by numbers at a distance"-approach derived from the inability and unwillingness to understand "the other." To "hunt" only for publications or grants threatens the professional self-understanding, a tendency judged as "colonizing" (Agyemang and Broadbent, 2015). The "pessimistic picture" Kallio and Kallio (2014) paint seems to become an inevitable reality. However, the tactics of resistance and symbolic use comprise two enabling aspects - the processes of communication enacted and the horizontal network-building - which direct toward subjectivisation as a non-deterministic process (Power, 2015). Paradoxically, dissent, resistance and symbolic use as tactics stabilize the system (Fleming and Spicer, 2003) but modify it also (Courpasson et al., 2012). Cultivating the tactics of resistance and symbolic use enables to deal with the unexpected, the complex and the ambiguous to a certain degree. A process we interpret as open-ended in its consequences so far.

\section{Conclusions and some further questions}

Because of the research interest to contribute to discourses in a literature, which analyzes alternate forms of use and unintended consequences of new calculative regimes put in place we refer to our research from more than a decade ago (Piber and Pietsch, 2006). We address the symbolic use of PMM in the Austrian HES at an early stage and continue this "thread of research" from a longitudinal perspective to answer the research question of how a 
calculative regime for public universities is implemented, how and under which conditions its symbolic use emerges and what kind of unintended consequences occur over time.

To identify two enabling consequences emerging from the tactical behaviors of resistance and symbolic use may seem surprising. However, this explicit contribution allows for developing a perspective of theory-building further and beyond the focus on how accounting begins. Taking the four-phase model of Power (2015) as a starting point we systematically analyze what happens after the beginning is set. We argue in favor of a longitudinal perspective because of its possible richness. We present emerging enabling effects such as the communicative culture between the organizational and field level, as well as the horizontal networks of mutual trust within the organizational level. There was hardly any focus on the "we" among the universities before changes in power relations and tactical behaviors occurred. These changes opened-up spaces for horizontal links in self-organized working groups on the organizational level related to the KBS. A longitudinal study is an appropriate approach to analyze changes in the self-understanding of the organizational field, what it means to be part of a group of art or technical universities and how it changes communicative processes between the Ministry and the universities but also between subgroups of the organizational level.

To extend the time horizon of Figure 1 toward the episodes after the beginning asks for developing conceptual ideas to explain the dynamics emerging after the beginning is set by policy. Analyzing content issues of our case inductively requires the introduction of the concept of power, changes in power relations and forms of resistance. However, it is also a theoretical incentive to better understand how it becomes possible that dissent, disappointment, disillusion and tactical behaviors are expressed and have an impact, in terms of destabilization and new fragility. What unfolds after the first infrastructure was established is, however, neither a complete repercussion (the KBS becomes abandoned) nor an inversion of power (the organizational level decides if the KBS is supported and in which way). Instead of a revolution it is more of an evolution, a re-elaboration processed in the ongoing interaction between the field level and the organizational level, as well as within the organizational level and its organizations. Furthermore, the aspect of subjectivisation, its non-deterministic and uncertain character may be conceptualized in more detail by introducing power, changes in power relations and forms of resistance. This allows for better judgment on existing spaces for organizational and individual maneuvers and how far individuals may go - either in adhering to norms accounting procedures demand or in resisting by one or more of the three forms presented. Whether subjectivisation is under or overstated, may be analyzed and argued for with more clarity by using the perspectives offered in this paper.

However, there are questions, which remain intriguing to us and may be a point of reference for further research: How long can the symbolic use continue to be symbolic? Is there a tipping point when a more substantial performance management emerges from the calculative regime infrastructures? Are the effects of calculative regimes and PMM on performance management in public universities less substantial as we might think? How are operational and tactical decisions influenced ex ante when new courses in teaching have to be developed, new research projects have to be initiated and the sustainability of third mission effects has to be demonstrated? Is this may be linked to different generations of academics in charge, where at present a generation is still in power to defend the traditional academic freedom and professional communities of practice by applying symbolic processes to cope with the epistemological clash of measurement and management?

Finally, we cautiously conclude on a phenomenon Argento et al. (2020) mention en passant: persistence. On the one hand, the NPM-rationale has never been left uncriticized as 
QRAM

18,2

the references in the introduction show and there is empirically-based literature which offers rich insights into the dysfunctional effects of "managerialism", drawing pessimistic pictures of anxiety, demoralization, resistance and colonization. On the other hand, despite widespread critique its arguments and warnings remain unheard. The question arises why practices provoking dysfunctional consequences are still in place but this question has not been answered yet profoundly. Looking more closely at enabling consequences from symbolic use and open resistance for persuasion our study may provide an initial answer to this question.

Our empirics show how, apart from the Ministry on the field level, some individuals in administrative contexts profit on the organizational level from the KBS because of its legitimatory function. Another aspect is the characteristic of cooperative resistance which leads to accommodation. Persistance becomes more probable than revolution insofar as tactical behaviors such as open resistance for persuasion and symbolic use comprise even enabling consequences. Such consequences are a new communicative culture between the organizational and field level, and the horizontal networks of mutual trust within the organizational level. Evolutionary change is a realistic option when iterative processes dominate.

These aspects could be at least part of an explanation why critique and evidence of dysfunctional consequences is presented convincingly, and at the same time individual and organizational tactics ease the burden, foster accommodation and stabilize the system of a calculative regime. Periods of disillusion may result in destabilization and activities to reelaborate the content of the infrastructure. However, changing the content of an infrastructure means that the infrastructure as a system remains.

\section{Notes}

1. www.fhstp.ac.at/de/newsroom/news/10-jahre-wissensbilanz-unidata[21JULY2019]

2. According to the federal system of Austria, public universities are financed by the federal government whereas private universities are financed by the regions (in German "Bundesländer") and have to be accredited. We focus on public universities where state funding is predominant and changes in the legal framework consequently highly relevant. The Austrian HES consists of 22 public universities, 21 universities of applied sciences and 16 private universities and 14 university colleges of teacher education.

\section{References}

Adler, P.S. and Borys, B. (1996), "Two types of bureaucracy: enabling and coercive", Administrative Science Quarterly, Vol. 41 No. 1, pp. 61-89.

Agostino, D. and Arnaboldi, M. (2017), "Rational and ritualistic use of key performance indicators in hybrid organizations", Public Money and Management, Vol. 37 No. 6, pp. 409-416.

Agyemang, G. and Broadbent, J. (2015), "Management control systems and research management in universities: an empirical and conceptual exploration”, Accounting, Auditing and Accountability Journal, Vol. 28 No. 7, pp. 1018-1046.

Ahrens, T. and Chapman, C. (2004), "Accounting for flexibility and efficiency: a field study of management control systems in a restaurant chain", Contemporary Accounting Research, Vol. 21 No. 2, pp. 271-301.

Aleksandrov, E. (2020), "Actor's reflexivity and engagement in the formation of new accounting tools during university hybridization”, Qualitative Research in Accounting and Management, Vol. 17 No. 1, pp. 51-81. 
Alexander, F.K. (2000), "The changing face of accountability", The Journal of Higher Education, Vol. 71 No. 4, pp. 411-431.

Anderson, G. (2008), "Mapping academic resistance in the managerial university", Organization, Vol. 15 No. 2, pp. 251-270.

\section{Austrian public universities}

Argento, D., Dobija, D. and Grossi, G. (2020), "The disillusion of calculative practices in academia”, Qualitative Research in Accounting and Management, Vol. 17 No. 1, pp. 1-17.

Bayrhammer, B. and Grancy, A. (2018), "Hochschulen an der Grenze des Machbaren”, Die Presse, March 31st.

Burchell, S., Clubb, C., Hopwood, A.G., Hughes, J. and Nahapiet, J. (1980), "The roles of accounting in organizations and society", Accounting, Organizations and Society, Vol. 5 No. 1, pp. 5-27.

Cai, Y. (2010), "Global isomorphism and governance reform in Chinese higher education", Tertiary Education and Management, Vol. 16 No. 3, pp. 229-241.

Catasus, B., Ersson, S., Gröjer, J.-E., Wallentin, F.Y. (2007), "What gets measured gets . . on indicating, mobilizing and acting", Accounting, Auditing and Accountability Journal, Vol. 20 No. 4, pp. 505-521.

Conrath-Hargreaves, A. and Wüstemann, S. (2019), "Multiple institutional logics and their impact on accounting in higher education: the case of German foundation university", Accounting, Auditing and Accountability Journal, Vol. 32 No. 3, pp. 782-810.

Courpasson, D. and Clegg, S. (2012), "The polyarchic bureaucracy: cooperative resistance in the workplace and the construction of a new political structure of organizations", in Courpasson, D., Golsorkhi, D. and Sallaz, J.J. (Eds), Rethinking Power in Organizations, Institutions, and Markets [Research in the Sociology of Organizations], Vol. 34, Emerald Group, Bingley, pp. 55-79.

Courpasson, D., Golsorkhi, D. and Sallaz, J.J. (2012), "Rethinking power in organizations, institutions, and markets: classical perspectives, current research, and the future agenda", in Courpasson, D., Golsorkhi, D. and Sallaz, J.J. (Eds), Rethinking Power in Organizations, Institutions, and Markets [Research in the Sociology of Organizations], Emerald Group, Bingley, Vol. 34, pp. 1-20.

Cox, J.W. and Hassard, J. (2007), "Ties to the past in organization research: a comparative analysis of retrospective methods", Organization, Vol. 14 No. 4, pp. 475-497.

Deem, R. and Brehony, K.J. (2005), "Management as ideology: the case of 'new managerialism' in higher education", Oxford Review of Education, Vol. 31 No. 2, pp. 217-235.

Dobija, D., Górska, A.M., Grossi, G. and Strzelczyk, W. (2019), "Rational and symbolic uses of performance measurement: experiences from Polish universities", Accounting, Auditing and Accountability Journal, Vol. 32 No. 3, pp. 750-781.

Erkkilä, T. and Piironen, O. (2014), "Shifting fundaments of European higher education governance: competition, ranking, autonomy and accountability", Comparative Education, Vol. 50 No. 2, pp. 177-191.

Espeland, W.N. and Sauder, M. (2007), "Rankings and reactivity: how public measures recreate social worlds", American Journal of Sociology, Vol. 113 No. 1, pp. 1-40.

Espeland, W.N. and Sauder, M. (2016), Engines of Anxiety. Academic Rankings, Reputation, and Accountability, Russel Sage Foundation, New York, NY.

Field, L. (2015), “Appraising academic appraisal in the new public management university”, Journal of Higher Education Policy and Management, Vol. 37 No. 2, pp. 172-189.

Fleming, P. and Spicer, A. (2003), "Working at a cynical distance: implications for power, subjectivity and resistance", Organization, Vol. 10 No. 1, pp. 157-179.

Fleming, P. and Spicer, A. (2008), "Beyond power and resistance: new approaches to organizational politics", Management Communication Quarterly, Vol. 21 No. 3, pp. 301-309. 
QRAM 18,2

Fleming, P. and Spicer, A. (2014), "Power in management and organization science", Academy of Management Annals, Vol. 8 No. 1, pp. 237-298.

Fraenkel-Haeberle, C. (2014), Die Universität im Mehrebenensystem. Modernisierungsansätze in Deutschland, Italien und Österreich, Mohr Siebeck, Tübingen.

Gornitzka, A. and Maassen, P. (2017), "European flagship universities: autonomy and change", Higher Education Quarterly, Vol. 71 No. 3, pp. 231-238.

Grossi, G., Kallio, K.-M., Sargiacomo, M. and Skoog, M. (2020), “Accounting, performance management systems and accountability changes in knowledge-intensive public organizations", Accounting, Auditing and Accountability Journal, Vol. 33 No. 1, pp. 256-280.

Habersam, M., Piber, M. and Skoog, M. (2013), "Knowledge balance sheets in Austrian universities: the implementation, use, and re-shaping of measurement and management practices", Critical Perspectives on Accounting, Vol. 24 Nos 4/5, pp. 319-337.

Habersam, M., Piber, M. and Skoog, M. (2018), "Ten years of using knowledge balance sheets in Austrian public universities: a retrospective and prospective view", Journal of Intellectual Capital, Vol. 19 No. 1, pp. 34-52.

Höllinger, S. (2004), "Die Entwicklung von der staatlich gelenkten zur autonomen und europäischen Universität”, in Höllinger, S. and Titscher, S. (Eds), Die Österreichische Universitätsreform. Zur Implementierung des Universitätsgesetzes 2002, WUVUniversitätsverlag, Wien, pp. 51-69.

Hood, C. (1995), “The new public management in the 1980's: variation on a theme", Accounting, Organizations and Society, Vol. 20 Nos 2/3, pp. 93-109.

Hopwood, A.G. (1983), "On trying to study accounting in the contexts in which it operates", Accounting, Organizations and Society, Vol. 8 Nos 2/3, pp. 287-305.

Hopwood, A.G. (1987), "The archaeology of accounting systems", Accounting, Organizations and Society, Vol. 12 No. 3, pp. 207-234.

Hopwood, A.G. (1992), "Accounting calculation and the shifting sphere of the economic", European Accounting Review, Vol. 1 No. 1, pp. 125-143.

Hopwood, A.G. (1996), "Looking across rather than up and down: on the need to explore the lateral processing of information", Accounting, Organizations and Society, Vol. 21 No. 6, pp. 589-590.

Johanson, U. and Skoog, M. (2015), Integrerad Verksamhetsstyrning, Studentlitteratur, Lund.

Jordan, S. and Messner, M. (2012), "Enabling control and the problem of incomplete performance indicators", Accounting, Organizations and Society, Vol. 37 No. 8, pp. 544-564.

Kallio, K.-M. and Kallio, T.J. (2014), "Management-by-results and performance measurement in universities - implications for work motivation”, Studies in Higher Education, Vol. 39 No. 4, pp. 574-589.

Kallio, T.J., Kallio, K.-M. and Blomberg, A. (2020), "From professional bureaucracy to competitive bureaucracy - redefining universities' organization principles, performance measurement criteria, and reasons for being", Qualitative Research in Accounting and Management, Vol. 17 No. 1, pp. 82-108.

Lukka, K. and Vinnari, E. (2014), "Domain theory and method theory in management accounting research", Accounting, Auditing and Accountability Journal, Vol. 27 No. 8, pp. 1308-1338.

Lynch, K. (2015), “Control by numbers: new managerialism and ranking in higher education”, Critical Studies in Education, Vol. 56 No. 2, pp. 190-207.

McNay, I. (1995), "From the collegial academy to corporate enterprise: the changing cultures of universities", in Schuller, T. (Ed.), The Changing University?, SRHE/Open University Press, Buckingham, pp. 105-115. 
Miller, P. (1992), “Accounting and objectivity: the invention of calculating selves and calculable spaces”, Annals of Scholarship, Vol. 9 Nos 1/2, pp. 61-86.

Miller, P. (1994), "Accounting as social and institutional practice: an introduction”, in Hopwood, A.G. and Miller, P. (Eds), Accounting as Social and Institutional Practice, Cambridge University Press, Cambridge, pp. 1-39.

Miller, P. and O'Leary, T. (1994), "Governing the calculable person”, in Hopwood, A.G. and Miller, P. (Eds), Accounting as Social and Institutional Practice, Cambridge University Press, Cambridge, pp. 98-115.

Miller, P. and Rose, N. (1990), "Governing economic life”, Economy and Society, Vol. 19 No. 1, pp. 1-31.

Mouritsen, J. (1994), "Rationality, institutions and decision making: reflections on March and Olsen's rediscovering institutions", Accounting, Organizations and Society, Vol. 19 No. 2, pp. 193-211.

Nash, K. (2019), "Neo-liberalisation, universities and the values of bureaucracy", The Sociological Review, Vol. 67 No. 1, pp. 178-193.

Osborne, D. and Gaebler, T. (1992), Reinventing Government: How the Entrepreneurial Spirit is Transforming the Public Sector, Addison-Wesley, Reading, MA.

Parker, L. (2011), "University corporatization: driving redefinition”, Critical Perspectives on Accounting, Vol. 22 No. 4, pp. 434-450.

Parker, L. (2012), "From privatised to hybrid corporatised higher education: a global financial management discourse", Financial Accountability and Management, Vol. 28 No. 3, pp. 247-268.

Parker, L. (2013), "Contemporary university strategising: the financial imperative", Financial Accountability and Management, Vol. 29 No. 1, pp. 1-25.

Piber, M. and Pietsch, G. (2006), "Performance measurement in universities: the case of knowledge balance sheets analyzed from a new institutional perspective", in Epstein, M. and Manzoni, J.-F. (Eds), Performance Measurement and Management Control: Improving Organizations and Society, Elsevier, Amsterdam, pp. 379-401.

Potter, B.N. (2005), "Accounting as a social and institutional practice: perspectives to enrich our understanding of accounting change", Abacus, Vol. 41 No. 3, pp. 265-289.

Power, M. (1994), The Audit Explosion, Demos, London.

Power, M. (1997), The Audit Society: Rituals of Verification, Oxford University Press, Oxford.

Power, M. (2015), "How accounting begins: object formation and the accretion of infrastructure", Accounting, Organizations and Society, Vol. 47 No. 1, pp. 43-54.

Secundo, G., Dumay, J., Schiuma, G. and Passiante, G. (2016), "Managing intellectual capital through a collective intelligence framework: an integrated framework for universities", Journal of Intellectual Capital, Vol. 17 No. 2, pp. 298-319.

Soh, K. (2017), World University Rankings. Statistical Issues and Possible Remedies, World Scientific, NJ.

Strauss, E. and Tessier, S. (2019), "Editorial. Enabling and coercive controls in the twenty-first century: future avenues for revisiting Adler and Borys", Qualitative Research in Accounting and Management, Vol. 16 No. 2, pp. 182-196.

Teelken, C. (2011), "Compliance or pragmatism: how do academics deal with managerialism in higher education? A comparative study in three countries", Studies in Higher Education, Vol. 37 No. 3, pp. 271-290.

Townley, B. (1997), “The institutional logic of performance appraisal”, Organization Studies, Vol. 18 No. 2, pp. 261-285.

UG (2002), “Universitätsgesetz, Bundesgesetzblatt für die Republik Österreich I Nr. 120/2002”, Wien. 
QRAM

18,2

194

Universitätsbericht (2017), "Bundesministerium für Wissenschaft, Forschung und Wirtschaft (bmwfw)", Wien, available at: www.bmbwf.gv.at/fileadmin/user_upload/Publikationen/ Universit\%C3\%A4tsbericht_2017_barrierefrei.pdf (accessed 22 May 2020).

WBV (2016), "Bundesgesetzblatt für die Republik Österreich II Nr. 97/2016”, Wien.

WBV (2017), "Wissensbilanzverordnung, Bundesgesetzblatt für die Republik Österreich II Nr. 69/ 2017", Wien.

Yin, R.K. (1994), Case Study Research - Design and Methods, 2nd ed., Sage, Thousand Oaks, CA.

Corresponding author

Michael Habersam can be contacted at: michael.habersam@uibk.ac.at

For instructions on how to order reprints of this article, please visit our website: www.emeraldgrouppublishing.com/licensing/reprints.htm

Or contact us for further details: permissions@emeraldinsight.com 